\title{
COVID-19: Impact on undergraduate nursing education in Sri Lanka
}

Ilankoon Mudiyanselage Prasanthi Sumudrika Ilankoon, ${ }^{1}$ Gnanaselvam Kisokanth, ${ }^{2}$ Sudath Shirely Pathmasiri Warnakulasuriya ${ }^{2}$

${ }^{1}$ Department of Nursing and Midwifery, Faculty of Allied Health Sciences, University of Sri Jayewardenepura, Gangodawila, Nugegoda; ${ }^{2}$ Department of Clinical Nursing, Faculty of Nursing, University of Colombo, Sri Lanka.

Correspondence: Dr. I. M. P. S. Ilankoon, Department of Nursing and Midwifery, Faculty of Allied Health Sciences, University of Sri Jayewardenepura, Gangodawila, Nugegoda, Sri Lanka.

E-mail: prasanthi@sjp.ac.lk

Tel.: +94774986623.

Key words: Nursing education; Sri Lanka; COVID-19; online distance learning; impact; professional development; nursing undergraduates.

Contributions: All authors of this article have contributed significantly to the manuscript and share the responsibility for the above. The manuscript has been read and approved by all the authors, and the requirements for authorship have been met, and each author believes that the manuscript represents honest work.

This article has been accepted for publication and undergone full peer review but has not been through the copyediting, typesetting, pagination and proofreading process, which may lead to differences between this version and the final one. Please cite this article as doi: 10.4081/jphr.2020.1916 
Funding: None.

Competing interests: The authors declare no conflict of interest.

Ethical approval: The authors of the present study were loyal to the intellectual property of the articles and avoided plagiarism. There was no human and animal based data collection involved in this study.

Availability of data and material: All the articles reviewed in this scoping review are included in the reference list.

\section{Significance for public health}

This article emphasizes the impact of COVID-19 pandemic on nursing education where the clinical training is a major component in nursing curricula. It prompts nursing academics to think advance on future educational needs of the world and how to adapt with the pandemic situations. It is an advantage for higher education institutions to facilitate nursing faculties to utilize new technologies and revise nursing curricular to use blended learning activities which would be the best approaches in future nursing education.

\section{Abstract}


"Novel Corona Virus" (COVID-19) is a new infectious disease spreading all around the world which has a significant morbidity and mortality globally at present. Nurses as frontline care provider in hospitals and community are exposed to a major risk. This brief report aims at providing an overview of COVID-19 impacts on Sri Lanka and to highlight educational implications from the perspective of nursing degree programs. The major impacts of COVID19 on nursing education were unequal access to online distance learning, disruption of academic calendars, cancellation of clinical placements, teaching and learning gap, lack of facilities for online learning, disruption towards professional development, and inability to conduct proper clinical assessments and standard operationalization procedures. It suggests that higher education institutions should take actions to provide material support for students from low-income households to close the gap between teaching and learning and training for academics on different online teaching strategies.

\section{Introduction}

During last two decades, there were several epidemics in some regions in the world such as severe acute respiratory syndrome coronavirus (SARS-CoV) from 2002 to 2003, H1N1 influenza in 2009, and the Middle East respiratory syndrome coronavirus (MERS-CoV) in $2012 .^{1}$ Following an outbreak of pneumonia of unknown reason was first reported on $31^{\text {st }}$ December 2019 from Wuhan City in Hubei Province of China, the disease was diagnosed as "Novel Corona Virus" (COVID-19). The pathogen for this pneumonia was subsequently, named as SARS coronavirus 2 by the International Committee on Taxonomy of Viruses. ${ }^{1-2}$ Since then, COVID-19 has made a huge impact socio-economically throughout the world.

COVID-19 is very contagious and the incubation period of the virus range from 2-14 days. ${ }^{3}$ It mainly transmits through the close contact and respiratory droplets. ${ }^{4}$ The most common 
symptoms at onset are fever, dry cough, fatigue. ${ }^{5}$ In severe illness includes severe pneumonia, ARDS, sepsis and septic shock. ${ }^{6}$ Further, older people, and those who have existing medical conditions are more likely to experience serious illness. ${ }^{7}$

It is evident that the COVID-19 pandemic would create a significant economic impact globally which will result in adverse outcomes in healthcare, social and economic sectors not only in the short term but also in medium and long term as well. ${ }^{8}$ Since the identification of the COVID-19 pandemic, it has affected educational systems worldwide, leading to the neartotal closures of schools, universities and colleges. ${ }^{9}$ As a low middle-income country, such a pandemic can potentially paralyze the Sri Lankan healthcare system with the lack of resources and the absence of an advanced primary health care system. This article aims at discussing major issues related to nursing education following the COVID-19 pandemic in Sri Lanka.

\section{Impact of COVID-19 in Sri Lanka}

At present, a total of 2,984 patients have been identified and 12 deaths related COVID-19 has been reported in Sri Lanka. Following the detection of first few patients in Sri Lanka, government declared closure of educational institutions similar to many countries who have controlled the spread of H1N1 flu pandemic in $2009^{4}$ followed by curfew for the entire country. This outbreak prompted the health authorities to implement a series of public health measures and hospital policies. At present, the health authorities have controlled the COVID19 clusters by using the strategy of contact tracing and case isolation ${ }^{10}$ and still continuing testing community and returnees from overseas.

\section{Materials and Methods}


This brief report was written based on preliminary observations and review of published literature on COVID-19, impact on education, nursing education and pandemics, online teaching in nursing education in data bases such as MEDLINE, EBSCOhost, PsycInfo and Google Scholar. The articles were selected through titles and abstracts by the first author of this paper in March- June 2020.

\section{Results}

\section{Impact of COVID-19 on education in Sri Lanka}

Most of the governments around the world temporarily closed educational institutions to contain the spread of the COVID-19 pandemic $^{11}$ as part of a physical distancing policy to slow the transmission and ease the burden on healthcare systems. ${ }^{12}$ But, these nationwide closures are impacting almost $70 \%$ of the world's student population. ${ }^{11}$ At the middle April 2020, approximately 1.723 billion learners have been affected due to school/university closures in response to the pandemic. ${ }^{9}$

It has been advised to continue learning through online/e-learning strategies, assigning reading and exercises and radio, podcast or television broadcasts of academic content during the COVID -19 pandemic by UNICEF. ${ }^{13}$ However, it is worthwhile to think about the impact of long term closure of educational institutions and shifting of means of education to distance learning especially on those who are living in poverty, and are likely to exacerbate existing inequalities despite the detrimental social and economic consequences brought about by the pandemic alone. ${ }^{12}$ The closure of universities has widespread implications for students, faculty, administrators, and the institutions themselves. ${ }^{9}$ 


\section{Challenges for undergraduate nursing education following COVID-19 pandemic}

The Open University of Sri Lanka is conducting a BSc Nursing degree program for registered nurses since 1995 using Open and Distance Learning mode. University of Sri Jayewardenepura, Sri Lanka, the first conventional university to initiate a BSc (Honours) in Nursing Degree, which is a Preregistration Degree course, in 2005. At present, six state universities offer nursing degrees. As these conventional universities mainly conduct face to face teaching than online teaching, nursing education in all these universities have been fully or partially affected by the COVID-19 pandemic.

The nurses training programs have been designed to equip nurses with competencies in providing safe and effective nursing care of high standard in a variety of settings. The fouryear degree program consists of lectures, tutorials, laboratory practice, clinical and community field experience, presentations, group work, research projects and a lot of extracurricular activities during the university life. Clinical training for students continues from first year to final year starting from basic nursing skills to advance nursing procedures. All these academic and extra-curricular activities lead the students to become competent with knowledge, skills, attitudes and team spirit and dedication to nursing. But COVID-19 has impacted towards the usual learning environment of the undergraduates leading major challenges to the faculties and the students.

It has been mentioned that medical education is grappling with the changes that have been made and attempting to consolidate these with their plan of career development. ${ }^{14}$ Similar efforts are present with the nursing education all around the world. All aspects of nursing activities are affected by this pandemic, and healthcare facilities have responded to nursing education and student clinical needs in a variety of ways. ${ }^{15}$ Some have restricted student presence in their organizations, while others welcome healthy students. ${ }^{15}$ 
All the teaching activities have been transformed to online distance learning via platforms like Zoom, Google classroom, WhatsApp groups and Learning Management Systems (LMS) etc. in nursing faculties in Sri Lanka. Similar to many lower middle income countries, lack of access to technology and fast, reliable internet access have been the major challenges for students in rural areas in Sri Lanka., ${ }^{9,16}$ There are many efforts raised by the higher education authorities such as providing free access to LMS, free data used for Zoom meetings by the Lanka Education And Research Network for academics. But the question remains whether all the students have technological means in terms of computers and/or smart phones and the required technological competency/support at their homes as they are coming from different social strata of the country. This is a devastating challenge for low-income countries where the nursing education is under low resources and lacks funding.

Furthermore, this would be an opportunity to train academics to use of new technologies and innovative teaching which can be continued after the pandemic. The majority of academics have no or little experience in online teaching where face-to-face teaching has been the preferred method of teaching/learning strategy in Sri Lanka to date. Furthermore, the replacement of in-person classes with online distance learning might create a loss of collaborative experiences, which leads to a significant detriment to education. ${ }^{14}$

It has been understood that undergraduates are losing a lot of advantages being with patient care and study the pathology and nursing care perspectives during this time. The procrastination of the clinical practice due to the pandemic and completing theoretical aspects of patient care leads to disturbing the flow of the knowledge distribution to the undergraduates. It is similar to the medical education where the cancellation of clerkships is a serious issue. ${ }^{14}$ Providing adequate Personal Protective Equipment (PPE) during clinical practice for undergraduate has not been solved at present in Sri Lanka similar to many other 
countries. ${ }^{16}$ Although, many developed countries use simulation, telehealth, and virtual reality to provide relevant clinical experiences during this pandemic ${ }^{16}$ the use of those technologies in the Sri Lankan setting is questionable. But using videos on simulation for different nursing procedures are under consideration with minimum facilities in faculties.

Further, personal and professional development of student through presentations, group work, and teamwork has been interrupted during this period of time. Academics need to come up with ways of achieving these objectives through the distance learning methods and try to produce a graduate who has all the components in graduate profile of the faculty, which is a huge responsibility.

Despite the uncertainty of the situation, it is always advisable to look at what previous pandemics taught us. It has been evidenced that nursing education has faced similar challenges during previous pandemics such as SARS, H1N1 etc. ${ }^{17}$ The SARS outbreak affected both clinical teaching and assessment in nursing education as clinical teaching at all hospitals were suspended from the beginning of the outbreak in Hong Kong. ${ }^{17}$ As a solution to that, the nursing training institutions have utilized alternative means of updating and assessing students' clinical knowledge and skills and the laboratories have been used to facilitate clinical practice and assessment. ${ }^{17}$ Furthermore, boosting morale and managing stress have been highlighted as essential ingredients to incorporate to the curriculum, ${ }^{17}$ which will help to undergraduate nurses to work with frontline nurses and get more exposure and confidence to work during a pandemic.

\section{Conclusions}

This paper exposes the main areas of impacts of COVID -19 towards nursing education as challenges faced by the undergraduate nurses to achieve the learning outcome through 
distance online methods and challenges faced by nursing academics who has to navigate the clinical and theoretical teaching towards distance online learning. It suggests facilitating distance learning by increasing the availability of technologies for students and academics, training on online teaching strategies for academics and improving infrastructure facilities for nursing skills labs for basic and advance nursing procedures.

\section{References}

1. Cascella M, Rajnik M, Cuomo A, et al. Features, Evaluation and Treatment Coronavirus (COVID-19). StatPearls Treasure Island (FL): StatPearls Publishing; 2020 .

2. Zheng YY, Ma YT, Zhang JY, Xie X. COVID-19 and the cardiovascular system. Nature Rev Cardiol 2020:17:259-60.

3. Epidemiology Unit, Ministry of Health and Indigenous Medical Services. Total Number Confirmed Deaths Details of COVID 19 diagnosed patients. 2020. Available from:

https://www.epid.gov.lk/web/index.php?option=com_content\&view=article\&id=228 \&lang=en, Accessed: 26.05.2020.

4. World Health Organisation. Modes of transmission of virus causing COVID-19: implications for IPC precaution recommendations. Scientific Brief, March, 1-3. 2020. Available from: https://www.who.int/news-room/commentaries/detail/modes-oftransmission-of-virus-causing-covid-19-implications-for-ipc-precautionrecommendations, Accessed: 30.04 .2020

5. Huang C, Wang Y, Li X, et al. Clinical features of patients infected with 2019 novel coronavirus in Wuhan, China. Lancet 2020;395:497-506. 
6. Ministry of Health Sri Lanka. Provisional Clinical Practice Guidelines on COVID-19 suspected and confirmed patients. Ministry of Health Sri Lanka, March 2020. Available from: http://www.epid.gov.lk/web/images/pdf/Circulars/Corona_virus/covid19_cpg_version_5.pdf, Accessed: 01.04.2020

7. Epidemiology Unit, Ministry of Health and Indigenous Medical Services. COVID 19 fact sheet (Issue 011); 2020. Available from: https://www.epid.gov.lk/web/index.php?option=com_content\&view=article\&id=228 \&lang=en, Accessed: 15.05.2020.

8. Directorate of Environmental Health, Occupational Health and Food Safety. Operational guidelines on COVID-19 outbreak for work settings (Issue April). Directorate of Environmental Health, Occupational Health and Food Safety, Ministry of Health and Indigenous Medical Services,Sri Lanka; 2020. Available from: https://eohfs.health.gov.lk/occupational/images/2020/Workplace_guidelines_for_prev ention_of_COVID-19.pdf, Accessed: 16.05.2020.

9. Mustafa N. Impact of the 2019-20 coronavirus pandemic on education. Available from: https://www.researchgate.net/publication/340849956_Impact_of_the_201920_coronavirus_pandemic_on_education.

10. Hellewell J, Abbott S, Gimma A, et al. Feasibility of controlling COVID-19 outbreaks by isolation of cases and contacts. Lancet Global Health 2020;8:e488-96.

11. UNESCO (2020). COVID-19 Educational Disruption and Response. Available from: https://en.unesco.org/covid19/educationresponse. Accessed: $16^{\text {th }}$ May 2020

12. Van Lancker W, Parolin Z. COVID-19, school closures, and child poverty: a social crisis in the making. Lancet Public Health 2020;5:e243-4. 
13. Bender L. Key Messages and Actions for Prevention and Control in Schools. In Key Messages and Actions for COVID-19 Prevention and Control in Schools. Education in Emergencies UNICEF, New York; March 2020.

14. Ferrel MN, Ryan JJ. The Impact of COVID-19 on Medical Education. Cureus $2020 ; 12: 10-3$.

15. Jackson D, Bradbury-Jones C, Baptiste D, et al. Life in the pandemic: Some reflections on nursing in the context of COVID-19. J Clin Nurs 2020;1-3. doi: 10.1111 jocn. 15257

16. Morin KH. Nursing Education After COVID-19: Same or Different? J Clin Nurs 2020. doi: $10.1111 /$ jocn. 15322

17. Thompson DR, Lopez V, Lee D, Twinn S. SARS - A perspective from a school of nursing in Hong Kong. J Clin Nurs 2004;13:131-5. doi: 10.1046/j.13652702.2003.00884.x. 